\title{
From the Perspective of the Theory of Charismatic Leadership to See How to Cultivate the Charisma of Class Tutors in the University
}

\author{
Hou Jun ${ }^{1}$ \\ (Department of Organization Management, Party committee, \\ Wuhan University of Technology, WuHan,HuBei,430070)
}

\begin{abstract}
:
the institution for class tutor of undergraduates is the combination of head teacher system of the class and the tutor system, the main purpose is to guide the students to know more about their majors, and to be better adapted and involved into the campus life. As one special organization, the class as a whole is more eager to need one "leader" with charisma, and one responsible charismatic class tutor would play very important role in the construction of completing the institution of class tutor in the university, as well as promoting the full development of healthy of the students.
\end{abstract}

Keywords: charisma; leadership; class tutor; cultivate

\section{Independent innovative research fund:} Supported by "the Fundamental Research Funds for the Central Universities"

In recent years, there are more and more researches about the class tutor system, and different scholars have different opinions and definitions. Peng Haoyi started his research from the special age of university students and their own physiological and psychological characteris- tics in China, and he thought the guidance of class tutors mainly relies on six parts, which are thought guidance, major guidance, study guidance, psychological guidance, full development guidance and class management guidance. Tang Yongjun also mentioned "guidance" in his definition of connotation of class tutor, from the aspect of management, and it is the gathering of behavior patterns which authorize to the people who is under management. The "guidance" from the class tutor is not only focusing on the guidance of study, but also to provide the guidance of future development for the students, and to help them to be the right person as well as talented people. While Luo Rong thought, the class tutors are required to focus on "study guidance", which means to guide the students in the professional way, to help them cultivate the study ability, especially self-study ability, to lead the students to have innovative study, thinking and practice in their majors. Through questionnaires and interviews, this paper found that simple lecture could not fully have the effect of guidance of class tutors, and it is required

\footnotetext{
${ }^{1}$ The Author Introduction

Hou Jun (1976 ),female,Shishou City of Hubei Province,Student Affairs Office of Wuhan University of Techno lo-

gy,Lecturer, Basic Principles of Marxism PhD,Specializing in Chinese Marxism,and management and decisionmaking of science and technology.

Contact number:13517288498 E-Mail:hj6543@163.com

Address:Department of Organization Management, Party committee, Wuhan University of Technology. Postcode: 430070
} 
for the class tutors to use their own charisma, which includes personal character, professional knowledge and capability, to truly convince the students and complete themselves by regarding the class tutors as the model.

\section{The theoretical connotation of charis- matic leadership}

The word "charisma" derives from the Greek "the gift from the god", which is used to describe the gift with one kind of mature and stable power that few people own to make others fascinated. ${ }^{[1]}$ The theory of charismatic leadership was introduced by American management scientist House in 1977. According to House, charismatic leaders could fully convince their subordinates to be willing to accept the right faith and be obedient to the orders of the leaders, and to make them have the sense of mission to realize the objective of the organization, etc. In the meantime, he also pointed out that the charismatic leaders have three personalities, which are strong confidence, trend to dominate others, and strong faith for themselves. ${ }^{[2]}$

As we all know, the biggest difference between university students and senior secondary school students is that the self-management ability and self control of the university students are far more better than senior secondary school students, but the university students suddenly transfer from restrained by others in senior secondary school to fully self-management in the university, it is still hard to them to adapt to the environment, and it would cause many ideological and psychological problems or many conflicts if not being guide on time. Since the university students are easy to be plasticized, and they are in the very important stage to form their view of world, view of life and value. In this key stage, it is very required to have class tutors who have special "charisma" to guide them, and the class tutors' guidance and personal charisma would affect and help the students to adapt to the campus life as soon as possible, to define the target of life, and to push them to continuously and strive for this target of life.

\section{The qualities for charismatic class} tutors to obtain

To one class, the class tutor is the leader of the class. It is objective to require a class tutor to obtain very rich professional knowledge, and to have capability to convince students as well as the personal charisma to affect them. In a conclusion, the charismatic class tutors are required to have five kinds of qualities, which are noble morality, emotional dedication, professional knowledge, positive incentive, and to be innovative.

\subsection{Quality of noble morality}

The morality of leadership is the most basic quality for one leader, which is composed by his or her own morality, personality, style, etc. And noble morality is the soul of charisma of leader, and only with noble morality, he or she could make the subordinates to respects, so as to form strong power to motivate and convince them, and guide them to imitate consciously. And for one class, the class tutor is their bellwether, which is requesting the class tutor to have good morality, to promote the strength of example, to affect students, educate students, and infect students with charisma of personality. Of course, the example is the premise, and guidance is the key point. Thereafter, only the class tutors could appears to be good teacher, be obedient to their responsibilities, as good as one's word, then finally to be the example imitated by the students, and guide the students to build right target of study and human principles, to be good teachers and friends of students, as well as their guide of study.

\subsection{Quality of emotional dedication}

Theoretically, class tutors are the "leader" of the class, but class tutors and students are not pure relation between boss and staff. People always say that teaching benefits teachers as well as students, and 
the relation between class tutors and students is a kind of peaceful and friendly relationship for teachers and students, who could learn from each other, make progress together during the contact. According to Einstein, "love is the best teacher". That means that the precondition for the class tutors to successfully do their job is to right their attitude, love the job being class tutor, care and love their students. Only with their own emotion, the students could be touched, so as to respect and love class tutors. In the work, it is necessary for class tutors to have more emotional communication with students, pay attention to their general life, and help them to solve psychological confusion and all kinds of incidents, finally to build close, peaceful, friendly, and harmonious relationship between teachers and students. But, when focusing on emotion, the class tutors could not indulge the students without principles, it is very necessary to convince the students with truth and emotion. Thereafter, to encourage class tutors to have more emotional input doesn't mean to put regulation and principle behind, and it is also very necessary to use the measure of regulations to strengthen the class management. ${ }^{[3]}$

\subsection{Quality of professional knowledge}

The main factor of charisma of leader is to have some special talents. One talented leader could open the gate of success for one agency or department, so as to make the others to produce the sense of recognition and admiration to accept and obey the management of leaders. To the class tutors, these effects of talents would be fully appeared on the quality of professional knowledge of class tutors, which means the "“guidance" of the class tutor is fundamentally focus on the guidance of professional study for students. To be objective, higher education is one kind of professional activity relies on professional classification to cultivate higher talents, and students would keep more focus on their majors. To the lower grade students who haven't touched professional education especially fresh students who just step into the university, they are very limited to understand their major, and most of them even only stay in the understanding of the characters." ${ }^{[4]}$ So, class tutors need to meet the psychological requirements of students to understand their majors, use their own specialty in majors, to provide professional guidance of major in the right time, and to fully understand the characteristics, advantages and future development of the majors, help students to build right ideology of majors, cultivate the spirit to love the major and dedicate to the major, finally increase the interests and confidence of students on study.

\subsection{Quality of positive incentive}

Sincere compliment could help people to rebuild confidence, and kind critique could also help people to make progress. It is necessary to have suitable incentives for the students during the work of class tutors, and honest praise from the heart would be sure to help to encourage the students. Class tutors could provide true compliment to students in the proper time, and to express the concern and trust to students through occasionally little praise and encouragement. Though, it is difficult for people to understand and accept critiques, while, quality of being in good medicine for health tastes bitter to the mouth advice when most needed is least heeded to line, wise class tutors could use kind critiques to frankly talk and communicate with students, listen to their suggestions and advice, as well as the voice from the heart, which could make students to fully understand their problem, and encourage them to correct the errors and be cautious with it. Thereafter, no matter the charismatic class tutors give critiques or praise, would have the effects to encourage the students, and win their respect and trust, so as to let them open heart to communicate with 
teachers, finally to have practical effects naturally during the work of class tutors.

\subsection{Quality of being innovative}

For charismatic class tutors, the innovation could not only stay in the field of expertise and related scientific research, it is necessary for them to use specific view to grasp the characteristics of times and really situation of students, so as to open mind, innovate style, jump out of constrained form, pattern or framework, and be brave to break the regular pattern, to innovate during the work, and use new and more effective ways and thoughts to solve the problems in the practical work, for example, to use varies of suitable educational ways in the different students. In the meantime, class tutors are required to have foresight and sagacity, to have strategic view, and to draw the blue print of future development for students based on current trend of major, so as to encourage them to work in the right way.

\section{The cultivation of charisma of class tutors}

In recent years, following the increase of the student recruitment of the university, and the gradual implementation of the policy of credit system, and this would make higher standard to the work of ideological and political education for the students. How to fully make effects of guidance of class tutors, how to guide students to become useful person to serve the nation, it is very important to build charisma of class tutors.

\subsection{Build good morality, and make good example to affect students}

According to Mengci, "to convince people, the best is to affect them with your morality, the second is to use your talents, the last and the worst is to use your power." So the successful class tutors, or the class leaders with charisma, if want to get the faith from the students, they would rely on their good morality, instead of power issued from the position of class tutors. As leader of the class, it would not be enough or stable to convince students with only principles or regulations. "Only people with richer knowledge would be regarded as teacher, only people with good morality would be regarded as good example", this sentence has explained the outside appearance in ethics and personal morality for a class tutor to behave as a teacher. it takes ten years to grow a tree and a hundred years to bring up a generation of good men. The class tutors are required to improve their personal morality and quality, to bring these good qualities to the class construction, to affect every student, to reach the goal of truly educating and cultivating students, through making good example in the class activities and general communication. In the meantime, the class tutors are required to carry the responsibility of ideological and political education, which need to convince students with morality by building good example of class tutor, and provide guidance in thinking and action, finally to be helpful for the ideological and political education in the university and make good effects.

\subsection{Promote talents from multiple ways, and actively guide the education of students}

As the class tutors, it is basic to have solid and rich expertise, to have rigorous attitude to teach, and one of the main tasks is to provide useful guidance to the students in their major study. In the traditional Chinese characters, "dao", which English translation is "Guidance", are combined with "road" and "crossing", which has the explanation of "taking others' hand to guide people in the crossing". To class tutors, it is very important to use their rich expertise to have professional guidance for the students. Firstly, when the fresh students come to the university, it is required for class tutors to have a lecture about the background and future development of the major, so as to help 
them to build the notion of their major, and help them to select courses according to the specialty and personal condition, to help them to prevent to choose in blind, and to increase the faith of study. Secondly, since a lot of students have the mind to be lazy after entering the university, and they don't have strong self-control in study. In this case, the class tutors of university are required to provide effective guidance closely around the subject of study, to help them to analyze the necessity to study hard in the university, and to motivate the students from inside, to cultivate their interests and passion in study. At last, the class tutors could use the advantages of scientific research to help students to make the preparation for the road to the science, and help them to build the idea of scientific research and nurture the interests in it through general study gradually. The talents of class tutors could be revealed in solid expertise, and could be used guidance and education of students, so as to lead them to study hard and strive for the future with all kinds of measures.

\subsection{Input sincere emotion, and solve the problem and care about students}

From the datum of the questionnaire and interview, $80 \%$ of charisma of successful class tutors are coming from the input of emotion, which means the class tutors are required to fully use their strength of the emotion to help the work of class. In the general work, class tutors need to focus on the life of students, care about their growth, think in their mind, consider and handle problems in the shoe of students, so as to really help them with true heart. In the meantime, class tutors need to communicate with students honestly, to know their true mind by deepening into their dormitories, to fully grasp the study and life condition and thinking of students, so as to concern and cherish students on the base of fully understand them, to touch them with honesty, and make deep friendship between teachers and students. Emotion is the basic connection of interrelationship, so to the relationship between class tutors and students. Beautiful youth and unforgettable friendship between class tutors and students would not only be one of the key factor to show charisma of class tutors, but also the precious spiritual treasure in their life. Only with real concern for the students by class tutors, who could walk close to the life of students, and involve into the class, then could provide better service to the students.

\subsection{Help students to build beautiful vision, and make rational plan to en- courage them}

The good leaders with charisma could attract and encourage people with really vision. ${ }^{[5]}$ This is the same truth to class tutors. Class as one organization is required to have its vision and target, and these need class tutors to help to define and build, then gradually help every student to improve their capability and position in the vision of the class. With clear target, there would be the direction to strive for, and students would not be wandering with confusion, which could work out splendid university life. As for the class tutors, they could use this vision to encourage and inspire students, to enforce the gathering and attraction of the class. That is to say, with the target of the class, students would have their dream, so as to have continuously uprising standard, to have forwarding motive, then to have the courage to get rid of difficulties. Therefore, for the class tutors who have great charisma, it is very important to build vision, to encourage students, and guide them to growth and make progress.

\section{Reference}

[1] Li Yinghua, "General Introduction of Theoretical Research of Charismatic Leader," Journal of Inner Mongolia Nor- 
mal University (Philosophy \& Social Science),pp.387,2007.

[2] Cheng Yahua, Yang Wei,Wang Caixia, "Brief Introduction of Charismatic Leader, "Modern Enterprise Education, pp. 73,2008.

[3] He Yilun,Zhang Xingxing, "Thinking on the Work of Undergraduate Class Tutors in the Higher Institute ,'Journal of Changsha Railway University, pp. 235,2006.

[4] Peng Haoyi, "The Exploration on Using the Guidance of Class Tutors in the University ,'Educator, pp. 52,2004.

[5] Xie Wenxin, "Five Effective Behaviors of Charismatic Leader ,"Market Modernization, pp. 257,2005. 